\title{
ZEITSCHRIFT
}

FUR

\section{PHYSIKALISCHE CHEMIE}

\author{
BEGRUNDET VON \\ WILH. OSTWALD UND J.H. VAN'T HOFF
}

HERAUSGEGEBEN

IM AUFTRAGE DER CHEMISCHEN UND DER PHYSIKALISCHEN GESELLSCHAFT

IN DER DEUTSCHEN DEMOKRATISCHEN REPUBLIK

YON

H.FALKENHAGEN, R. ROMPE,

F. SAUERWALD, K. SCHWABE, A. SIMON, E. THILO

\section{BAND 219}

MTT 200 ABBILDUNGEN UND 23 TABELLEN

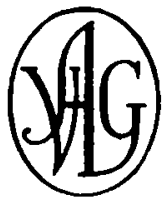

1962

AKADEMISCHE VERLAGSGESELLSCHAFT GEEST \& PORTIG K.-G. • LEIPZIG 